\title{
VIOLÊNCIA SEXUAL NA INFÂNCIA E ADOLESCÊNCIA: CARACTERÍSTICAS DA VIOLÊNCIA E PERFIL DAS VÍTIMAS NO MUNICÍPIO DE FEIRA DE SANTANA, BAHIA.
}

\author{
Daniela Pereira Portugal Souza $^{1}$; Jamilly de Oliveira Musse²; Anna Carolina Rocha da \\ Silva $^{3}$; Francinny Sousa Maciel ${ }^{4}$ \\ 1. Bolsista PIBIC/FAPESB, Graduanda em Psicologia, Universidade Estadual de Feira de Santana, e-mail: \\ danielapportugal@gmail.com \\ 2. Orientador, Departamento de Saúde, Universidade Estadual de Feira de Santana, e-mail: musse_jo@ hotmail.com. \\ 3. Graduanda em Farmácia, Departamento de Saúde, Universidade Estadual de Feira de Santana, e-mail: \\ annacarolinarocha@hotmail.com.br \\ 4. Graduanda em Medicina, Departamento de Saúde, Universidade de Feira de Santana, e-mail: \\ francinnymaciel@ hotmail.com
}

PALAVRAS-CHAVE: Violência sexual; Crianças; Adolescentes.

\section{INTRODUÇÃO}

Devido à alta incidência e às sérias consequências para vítima, sua família e à sociedade, a violência sexual contra crianças e adolescentes na contemporaneidade é considerado um grave problema de saúde pública, fato apontado também pela Organização Mundial de Saúde, o que suscita a necessidade de medidas preventivas e protetivas ao abuso sexual (HABIGZANG et al., 2005; OMS, 2002).

A definição de violência sexual em suma é apresentada como "qualquer ato sexual, tentativa de obter um ato sexual, comentário ou investidas sexuais indesejadas, ou atos direcionados ao tráfico sexual ou de alguma forma voltados contra a sexualidade" (OMS, 2002 , p. 147). No que concerne ao abuso sexual, ocorre entre "uma criança ou adolescente e alguém em estágio psicossexual mais avançado do desenvolvimento, no qual a criança ou adolescente estiver sendo usado para estimulação sexual do perpetrador" (HABIGZANG et al., 2005, p. 341). O abuso sexual pode ser empreendido: com contato através de "interação sexual, pode incluir toques, carícias, sexo oral ou relações com penetração (digital, genital ou anal)"; e sem contato como no voyerismo, assédio e exibicionismo (HABIGZANG et al., 2005, p. 341). Os contextos de ocorrência do abuso sexual são classificados em extrafamiliar e intrafamiliar (COSTA, 2013). O abuso sexual intrafamiliar é "considerada como incestuoso, ocorre no espaço social interno da família, seja ela biológica ou adotiva." (SANTOS, 2011, p. 65; COSTA, 2013). O abuso sexual extrafamiliar pode ser definido como o ato no qual uma pessoas conhecidas ou desconhecidas estabelecem atividade sexual com criança(s) ou adolescente(s) e sua ocorrência pode ser nos espaços de socialização da vítima ou ambientes desconhecidos (NEVES et al., 2010; SANTOS, 2011).

A Organização Mundial de Saúde indica a necessidade da realização de pesquisas nos países para que o fenômeno da violência sexual e consequentemente o abuso sexual, seja conhecido a partir da realidade de cada nacionalidade (OMS, 2002). Em consonância, a pesquisa apresenta relevância científica e social, na medida em que: se apresenta como um estudo específico, que investiga os aspectos relativos ao perfil das crianças e adolescentes vítimas de violência sexual e as característica do abuso, a nível municipal; e possibilita na identificação de como a violência sexual tem atingido população infanto-juvenil em Feira de Santana. Nesse sentido, a presente pesquisa teve por objetivo geral descrever e analisar o perfil das vítimas de violência sexual perpetrada contra crianças e adolescentes e as características da violência em Feira de Santana, Bahia.

\section{MATERIAL E MÉTODOS OU METODOLOGIA (ou equivalente)}


Trata-se de um estudo de corte transversal, de caráter descritivo e exploratório, com base em dados secundários referentes à violência sexual de crianças e adolescentes, registrados nos Boletins de Ocorrência (BO), Termo Circunstanciado (TC) e Relatórios dos Inquéritos Policiais (IP) das Delegacias de Polícia Civil Especializadas (Delegacia de Repressão ao Crime Contra a Criança e o Adolescente - DERCA, Delegacia do Adolescente Infrator - DAÍ, Delegacia Especializada de Atendimento à Mulher - DEAM), de Feira de Santana-BA, Brasil, no período de $1^{\circ}$ de janeiro de 2005 a 31 de dezembro de 2010. Para tanto, foi utilizado como instrumento formulário estruturado, no qual constam as seguintes variáveis: 1) Ocorrência e denúncia; 2) Informações sobre a criança/adolescente vitimizado; 3) Informações referentes ao agressor/perpetrador da violência sexual; 4) Outras informações sobre a ocorrência. Na elaboração do banco de dados foi utilizado o software Epidata, versão $3.1 \mathrm{~b}$, as análises foram realizadas através dos programas estatísticos Statistical Package for Social Sciences - SPSS, versão 10.0., e para evitar a duplicidade utilizou-se o Linkage. Para a análise descritiva foram calculadas as frequências (absoluta e relativa) dos dados referentes ao perfil sóciodemográfico do agressor e características da ocorrência. Na análise exploratória, foram realizadas análises bivariadas, para avaliar possíveis associações entre dados do agressor e características da ocorrência (violação), assim como dados do agressor utilizandose como medida de associação a razão de prevalência (RP), com seus respectivos intervalos de confiança de 95\% (IC 95\%), tendo como medida de significância estatística o teste de Quiquadrado de Pearson $(\chi 2)$, com valor de $p \leq 0,05$.

O presente trabalho integra a proposta do projeto Rede de proteção e prevenção da violência e garantia dos Direitos Humanos: Integração Universidade e Sistemas de Segurança Pública, atendimento e defesa da infância, adolescência e juventude e foi aprovado pelo Comitê de Ética em Pesquisa da Universidade Estadual de Feira de Santana, com protocolo de $n^{\circ} 143 / 2010$ (CAAE $n^{\circ}$ 0141.0.059.000-10), em conformidade com a resolução no 466/12 do Conselho Nacional de Saúde. A coleta de dados foi autorizada pela Coordenação Regional da Policia Civil de Feira de Santana (Departamento de Polícia do Interior - DEPIN; $1^{\text {a }}$ Coordenaria de Polícia do Interior $-1^{a}$ COORPIN).

\section{RESULTADOS E DISCUSSÃO}

No período no qual compreende a pesquisa, foram notificados 618 casos de vitimização sexual de crianças e adolescentes, registradas nas Delegacias de Polícia Civil e Especializadas (DEAM, DAÍ e DERCA) na cidade de Feira de Santana, Bahia. Em síntese, o perfil das vítimas em Feira de Santana, entre os anos de 2005 a 2010, apresentou as seguintes características: $81,2 \%$ sexo feminino; $45,1 \%$ com idade entre $11-14$ anos; $75,7 \%$ de cor parda; $89,6 \%$ estudavam; 64,4\% apresentavam ensino fundamental incompleto; 63,9\% moravam apenas com a mãe.

Os dados apontaram que o abuso sexual apresentou-se como o tipo de violência sexual mais frequente $(94,2 \%)$, enquanto que a exploração sexual correspondeu a $5,8 \%$ dos casos. Entretanto, conforme indicado pela pesquisa de tráfico e exploração de crianças e adolescentes - PESTRAF, Feira de Santana foi considerada como zona de risco para a vitimização sexual de crianças e adolescentes, principalmente para a exploração sexual, devido à localização com proximidade da capital do estado (Salvador), que se constitui como polo turístico (LEAL, 2003). Além disso, 41,8\% das ocorrências de violência sexual eram reincidentes e entre as vítimas, houve predominância de violação no sexo feminino $(81,2 \%)$, independente do sexo do abusador (80,98\% masculino e $77,78 \%$ feminino). Em estudo realizado a partir dos casos notificados no município de Londrina-PR, no ano de 2006, 36,6\% das ocorrências indicaram mais de um episódio de vitimização e também houve o predomínio de vítimas sexo feminino (74,2\%) (MARTINS; JORGE, 2010) É importante destacar que as vítimas do sexo masculino correspondem a 116 dos casos registrados $(18,8 \%)$ no período de 
cinco anos. As crianças totalizaram 42,2\% dos casos e os adolescentes representaram 57,8\% das vítimas. O Sistema de Vigilância de Violência e Acidentes, entre 2009 e 2010, indicam que das queixas de violência contra crianças de até nove anos, 35,6\% correspondem às denúncias de violência sexual e 30,4\% correspondem aos adolescentes (BRASIL, 2013). Os pais foram os principais denunciantes $(63,4 \%)$ e as mães realizaram $52,8 \%$ das denúncias. No Rio Grande do Sul, entre 1992 e 1998, 37,6\% das denúncias foram realizadas pela mãe da vítima (HABIGZANG et al., 2005).

Quanto ao local de ocorrência, o ambiente doméstico foi identificado como o espaço mais frequente $(61 \%)$ de ocorrência da violência sexual. Entretanto, apresenta diferencial no que concerne ao contexto de ocorrência do abuso, pois a maioria se deu no contexto extrafamiliar (72,3\%), e em contrapartida o intrafamiliar representou 27,7\% dos casos. Cabe indicar também que os perpetradores conhecidos da vítima, violentaram ambas as faixas, da infância $(46,9 \%)$ e adolescência $(53,1 \%)$, com maior frequência de violação do sexo feminino (77,6\%). A Organização Mundial da Saúde que a violência sexual contra crianças e adolescentes geralmente tem como principal agressor, familiares ou pessoas que possuem vínculo com a família do vitimizado (OMS, 2002). Em estudo realizado por (MARTINS; JORGE, 2010), na cidade Londrina, 58,6\% dos agressores eram familiares ou faziam parte da família (p. ex. padrastos), enquanto que $35,5 \%$ eram conhecidos da vítima. No que concerne à manifestação do abuso, com contato físico representou 88,3\%, e dentro da categoria os abusos com penetração foram de $66,7 \%$. Em contrapartida, as formas de manifestação sem contato físico corresponderam a $11,7 \%$. Em $42,9 \%$ das vitimizações sexuais ocorreram em concomitância com a agressão física, o que representa 32,2\% das formas de intimidação física, correspondendo a uma das mais frequentes, juntamente com a sedução (42,7\%). Em Londrina (PR), verificou-se que 92,9\% das vítimas apresentaram consequências físicas inerentes à situação de abuso sexual (MARTINS; JORGE, 2010).

Torna-se relevante indicar que quanto aos agressores o perfil mais frequente foi do sexo masculino $(98,0 \%)$, cor parda $(68,4 \%)$; solteiro $(61,3 \%)$; de baixa escolaridade $(78,1 \%)$; empregado (86,8\%); não utilizava substâncias psicoativas $(87,1 \%)$; não apresentava histórico de detenção $(82,5 \%)$ ou não era processado por outras vitimizações sexuais $(75,1 \%)$. Em suma, a maioria das ocorrências envolveu um agressor (86,4\%). $\mathrm{O}$ agressor feminino $(2 \%)$ mostra maior proporção de violação na infância $(88,8 \%)$ e no sexo feminino $(77,7 \%)$, sendo a maioria nas faixas da infância (70,1\%). Em Porto Alegre, entre os anos de 2003 e 2007, foi observado que 6\% dos abusadores representavam o sexo feminino (PINCOLINI; HUTZ, 2014). No estudo de (MARTINS; JORGE, 2010), realizado em Londrina-PR, no ano de 2006, observou-se também a presença de mulheres entre os agressores $(2,1 \%)$. Na pesquisa também se verifica que os perpetradores adolescentes (29\%) vitimizaram, indistintamente, ambos os sexos $(45,0 \%$ e $54,9 \%)$. Entre as vítimas dos perpetradores adolescentes, $70 \%$ estavam na infância (0-11 anos). No estudo de (PINCOLINI; HUTZ, 2014), 27,5\% dos abusadores eram adolescentes, entretanto, o perfil das vítimas de abusadores adolescentes foi do sexo masculino $(61 \%)$.

\section{CONSIDERAÇÕES FINAIS}

No período de 2005 a 2010, que corresponde a cinco anos, 618 casos de violência sexual contra crianças e adolescentes foram registrados nas Delegacias de Polícia Especializadas. Quanto à caracterização da violência, o abuso sexual apresentou-se como o tipo de violência sexual mais frequente $(94,2 \%)$ e $41,8 \%$ das ocorrências de violência sexual eram reincidentes. $\mathrm{O}$ ambiente doméstico foi identificado como o espaço mais frequente (61\%) de ocorrência, entretanto, a maioria se deu no contexto extrafamiliar $(72,3 \%)$ e os pais foram os principais denunciantes $(63,4 \%)$. A forma mais frequente de denúncia ocorreu pessoalmente $(87,7 \%)$. Os perpetradores conhecidos da vítima violentaram mais e ambas as 
faixas, da infância $(46,9 \%)$ e adolescência (53,1\%). A intimidação física $(32,2 \%)$ correspondendo a uma das mais frequentes de coação, juntamente com a sedução $(42,7 \%)$. A maioria das ocorrências envolveu um agressor $(86,4 \%)$.

O perfil mais frequente das vítimas foi $81,2 \%$ sexo feminino; $45,1 \%$ com idade entre 11-14 anos; 75,7\% de cor parda; $89,6 \%$ estudavam; $64,4 \%$ apresentavam ensino fundamental incompleto; $63,9 \%$ moravam apenas com a mãe. As crianças totalizaram 42,2\% dos casos e os adolescentes representaram $57,8 \%$ das vítimas e $89,6 \%$ estudavam. O maior percentual de agressores foi do sexo masculino $(98,0 \%)$, cor parda $(68,4 \%)$; solteiro $(61,3 \%)$; de baixa escolaridade $(78,1 \%)$; empregado $(86,8 \%)$; não utilizava substâncias psicoativas $(87,1 \%)$; não apresentava histórico de detenção $(82,5 \%)$ ou não era processado por outras vitimizações sexuais $(75,1 \%)$. O agressor feminino $(2 \%)$ mostra maior proporção de violação na infância $(88,8 \%)$ e no sexo feminino $(77,7 \%)$, sendo a maioria nas faixas da infância $(70,1 \%)$. Entre os agressores, $29 \%$ perpetradores eram adolescentes e vitimizaram 45,0\% de crianças e adolescente do sexo masculino e 54,9\% do sexo feminino. Entre as vítimas de perpetradores adolescentes, $70 \%$ estavam na infância. Em 42,9\% das vitimizações sexuais ocorreram em concomitância com a agressão física.

As discussões realizadas no decorrer da exposição dos resultados pesquisa corroboram com outros estudos que se dedicaram ao tema em outros locais do país. Entretanto, os principais diferenciais encontrados nos registros de violência sexual contra crianças e adolescentes em Feira de Santana, estão: 1) no contexto de ocorrência do abuso enquanto extrafamiliar e na vinculação do agressor como alguém conhecido, pois geralmente em outras pesquisas as vitimizações no contexto intrafamiliar e consequentemente por um familiar são mais frequentes; 2) Os adolescentes vitimizaram crianças e adolescentes em ambos os sexos, embora outras pesquisas apontem a predominância de um.

\section{REFERÊNCIAS}

BRASIL. 2013. Sistema de Vigilância de Violência e Acidentes (VIVA), 2009, 2010, 2011. Brasília: Ministério da Saúde, 164p.

COSTA, M. C. O. 2013. Violência e vitimização na infância e adolescência. A inclusão da escola no reconhecimento e prevenção. UEFS Editora: Feira de Santana, 80p.

HABIGZANG, L. F.; KOLLER, S. H.; AZEVEDO, G. A.; MACHADO, P. X. 2005. Abuso Sexual Infantil e Dinâmica Familiar: Aspectos Observados em Processos Jurídicos. Psicologia: Teoria e Pesquisa, Brasília. 21 (3): 341-348.

LEAL, M. L.L. 2003. PESTRAF - Pesquisa sobre Tráfico de Mulheres, Crianças e Adolescentes para fins de Exploração Sexual Comercial: Relatório Nacional - Brasil. Brasília: CECRIA, $280 \mathrm{p}$.

MARTINS, C. B. G.; JORGE, M. H. P. M. 2010. Abuso sexual na infância e adolescência: Perfil das vítimas e agressores em município do sul do Brasil. Texto Contexto Enferm, Florianópolis, v. 19, n. 2, p. 246-55, Abr-Jun.

NEVES, A. S.; CASTRO, G, B.; HAYECK, M.; CURY, D. G. 2010. Abuso sexual contra a criança e o adolescente: reflexões interdisciplinares. Temas em Psicologia, Ribeirão Preto, 18 (1): 99-111.

ORGANIZAÇÃO MUNDIAL DE SAÚDE. 2002. Relatório Mundial sobre Violência e Saúde. OMS: Genebra, 380p.

PINCOLINI, A. M. F.; HUTZ, C. S. 2014. Abusadores Sexuais Adultos e Adolescentes no Sul do Brasil: Pesquisa em Denúncias e Sentenças Judiciais. Temas em Psicologia, v. 22, n. 2, 301-311

SANTOS, B. R. 2011. Guia escolar. Identificação de sinais de abuso e exploração sexual de crianças e adolescentes. Ministério da Saúde, 242p. 